\title{
Proyecto Termas Romanas en Hispania. Balance de una década de investigación (1993-2003) ${ }^{1}$
}

Carmen Fernández Ochoa, Virginia García-Entero,

Angel Morillo Cerdán y Mar Zarzalejos Prieto

\section{Resumen}

En el presente artículo realizamos un balance de la investigación realizada entre 1993 y 2003 en el Proyecto "Termas Romanas en Hispania" llevado a cabo en el Dpto. de Prehistoria y Arqueología de la UAM. Este proyecto, conformado por 3 consecutivos, se ha desarrollado al socaire de la propia investigación sobre termas generada en todo el occidente romano y del propio impulso que la arqueología urbana ha protagonizado en nuestra península y que ha permitido conocer un número significativo de termas públicas y balnea privados. Presentamos los principales trabajos que se han ocupado sobre las termas de Hispania así como las conclusiones básicas generadas por cada uno de los proyectos de investigación desarrollados y centrados en distintos aspectos de las instalaciones balnearias (sistema de calefacción, arquitectura, análisis funcional y decoración).

Palabras clave: Termas, Hispania, investigación

\begin{abstract}
In this paper we evaluate the investigation carried out by the Prehistory and Archaeology Department of the UAM university between 1993 and 2003 under the Project Roman Baths in Hispania. The project, conformed by three consecutive projects, has been developed boosted by the investigation of baths in all the Roman Western Empire and by the interest in urban archaeology aroused in our peninsula, which has led us to know a significant number of public baths and private balnea. We present the main works on the Baths of Hispania as well as the basic conclusions generated by each one of the research projects developed and focused on different aspects of the bath facilities (heating system, architecture, functional analysis and decoration)
\end{abstract}

Key words: Thermal complex, Hispania, research

En 1989, al excavar la muralla de Gijón en los jardines próximos al lugar en el que estaban soterradas las termas descubiertas parcialmente en 1903, comprobamos que dicha muralla encerraba dentro de su perímetro el edificio termal y se suscitaron de nuevo numerosos interrogantes sobre este importante conjunto romano que permanecía olvidado. El Ayuntamiento de Gijón impulsó la reexcavación de las viejas termas con

1 El presente trabajo se inscribe dentro del proyecto de investigación Termas romanas en Hispania: Programas decorativos y ambiente interior, financiado por el MCyT (BHA2000-0202) y dirigido por Carmen Fernández Ochoa.

2 Excavaciones dirigidas por C. Fernández Ochoa y P. el fin de comprobar el estado de conservación de la instalación, y las posibilidades ulteriores de su exhibición pública. Durante tres años consecutivos se llevaron a cabo estas excavaciones ${ }^{2}$ y finalmente, se adecuaron los restos, excepcionalmente bien conservados, creándose en 1995 un museo que engloba el edificio termal y parte de la muralla tardorromana ${ }^{3}$.

García Díaz dentro del "Proyecto Gijón de Excavaciones Arqueológicas"

3 La adecuación museística de los restos gijoneses fue galardonada con la Special Commendation del EMYA en 1996 . 
La excavación de esta instalación termal supuso el impulso para iniciar un estudio más amplio sobre los complejos balnearios hispanos, tema éste muy poco trabajado dentro de los estudios hispanorromanos. Al empezar nuestra investigación, el bagaje documental entonces disponible $^{4}$ nos convenció de la necesidad de emprender un proyecto de investigación de mayor alcance que el mero estudio de las termas gijonesas. Así fraguó la propuesta de elaborar un proyecto de investigación que ofrecimos a la DGICyT en 1992 (PS92-0025) y que se aprobó bajo el título Termas romanas públicas y baños privados en Hispania con una duración de tres años entre 1993 y 1995, proyecto que se vio consolidado con la concesión de dos nuevos consecutivos realizados hasta el 2003 en el marco del Departamento de Prehistoria y Arqueología de la UAM.

\section{1.- UN PRIMER PROYECTO COMO PUNTO de PaRTida. Catalogación Y eStudio de LOS SISTEMAS DE CALEFACCIÓN TERMAL EN HISPANIA.}

El objetivo primordial de este primer proyecto consistía en la elaboración de un catálogo completo y actualizado de los establecimientos termales conocidos en Hispania tomando como base el estudio de las partes mejor conservadas, esto es, de los hypocausta o sistemas de calefacción. Se trataba, en principio, de esclarecer si las características estructurales de los sistemas de calefacción obedeceran o no a razones de índole cronológica, geográfica o cultural. En este sentido, nos parecía importante valorar las posibles adaptaciones de los modelos itálicos, así como la vinculación de una morfología determinada con unos fines precisos en cada edificio.

\section{1.- ESTADO DE LA CUESTIÓN}

En el momento de abordar el primer proyecto partíamos de la evidencia de que los edificios termales constituyen una de las manifestaciones arquitectónicas más populares y frecuentes en el mundo romano. Las fuentes textuales contienen referencias expresivas acerca de su arraigo en la sociedad romana e, incluso, a través de ellas percibimos la génesis de un modelo constructivo adaptado a la función y uso de estos edificios. Lógicamente, son las fuentes arqueológicas las que refrendan la difusión de un modelo genérico, que sufrirá una evolución pareja al descubrimiento de nuevas fórmulas técnicas (hypocaustum, concamerationes, etc.). Este arquetipo se adaptará a las necesidades y posibilidades de cada núcleo urbano, en el caso de las termas públicas, o de cada propietario en el caso de los balnea privados.

El panorama investigador fuera de nuestras fronteras mostraba una orientación preferente de estos estudios hacia cuestiones relacionadas con las grandes edificaciones termales de $\operatorname{Roma}^{5} \mathrm{y}$ otros importantes centros del solar italiano, como Ostia Antica ${ }^{6}$, Pompeya ${ }^{7}$, Baia o Pisa. A la par, se venían desarrollado trabajos sobre conjuntos situados en el limes germánico (Trier, Saalburg,

mente), reuniones que tuvieron su consecución en 1992 en la ciudad de Bath (DeLaine y Johnston, 1999). Las aportaciones más recientes se ajustan también a la doble línea que tipifica la década anterior. A título de ejemplo, han aparecido algunas monografías, como la de las termas del Foro de Ostia (Cicernia y Marinuchi, 1992), el gran complejo imperial de Caracalla (DeLaine, 1997), los edificios de Lycia (Farrigton, 1995) además de los excelentes trabajos de carácter general de I. Nielsen (1990), F. Yegül (1992) y F. G. Fagan (1999 y 2001).

5 A los clásicos trabajos sobre los grandes complejos termales imperiales de la ciudad se ha sumado recientemente el ya mencionado trabajo de J. DeLaine sobre las Termas de Caracalla (1997).

6 Diversos estudios y monografías se han ocupado parcial o puntualmente de los complejos termales ostienses. Entre ellos, y al margen del ya citado sobre las Termas del Foro de P. Cicerchia y A. Marinucci (1992), cabe destacar los de E. A. Thatcher (1956), F. Zevi y V. Mannucci (1980) o C. Panella (1978). A estos trabajos se suma la obra de síntesis de $\mathrm{M}^{\mathrm{a}}$ A. Ricciardi (1997), así como los estudios realizados por R. Mar sobre diversos complejos termales de la ciudad (Mar Medina, 1990, 1991 y 2001).

7En esta ciudad, además de los clásicos trabajos centrados en los grandes complejos públicos, han visto la luz en la última década monografías sobre otras instalaciones como Las Termas del Sarno (Koloski Ostrow, 1990) o las Termas Suburbanas (Jacobelli, 1995). 
etc.), Britania (Chesters, Caerion, Exeter, Bath, entre otros), las Galias (Seviac, Sens, provincia Narbonense $^{8}$ ) y el Norte de África ${ }^{9}$. Al margen de estos trabajos, habían salido a la luz dos importantes monografías de cobertura más amplia ${ }^{10}$ que ofrecían un buen punto de partida para la comprensión del fenómeno termal en el mundo romano.

En Hispania, el acercamiento a esta cuestión planteaba numerosos problemas metodológicos. Así, al iniciar nuestra investigación y como ya pusimos de manifiesto en otra ocasión ${ }^{11}$, contábamos con excavaciones en algunos complejos termales ltalica $^{12}$, Carteia ${ }^{13}$, Hispalis ${ }^{14}$, Azaila ${ }^{15}$, Arcobriga ${ }^{16}$, Emporiae $^{17}$, Gijón ${ }^{18}$, Lancia ${ }^{19}$, Asturica Augusta ${ }^{20}$, Legio ${ }^{21}$, Baetulo ${ }^{22}$, Barcino o Segobriga ${ }^{24}$, entre otrosque ponían de manifiesto la riqueza y la antigüedad de algunos de estos monumentos, analizados con mayor profundidad en los últimos años ${ }^{25}$. La falta de una moderna metodología aplicada a la excavación de estos conjuntos, planteaba problemas de interpretación que sólo una revisión o la aplicación de nuevos enfoques y tecnologías podría subsanar en alguna medida.

8 De esta provincia destacan los trabajos del profesor A. Bouet que engloban la totalidad de instalaciones termales -públicas y privadas- (Bouet, 1996, 2003) así como el análisis del material empleado en su construcción (Bouet, 1999).

9 las visiones de síntesis es obligado citar las obras de Y. Thébert (1991 y 2003) y É. Lenoir (1991), así como trabajos monográficos sobre algunos edificios entre los que destacamos el de H. Broise e Y. Thébert sobre las termas Memmianas de Bulla Regia (Broise y Thébert, 1993), el de H. Zehnacker y G. Hallier sobre Volubilis (1965) -al que añadimos el ya clásico de R. Étienne sobre esta misma ciudad (1960)-, el de R. Thouvenot y A. Luquet sobre Banasa (1951) o el de R. Rebuffat, G. Hallier y J. Marion sobre Thamusida (1970).

10 Nielsen, 1990 y Yegül, 1992 a los que cabe sumar, más recientemente el trabajo de Fagan, 1999.

11Fernández Ochoa, Morillo, Zarzalejos y García- Entero, 1997.

12 Las dos grandes instalaciones termales públicas de la ciudad -Termas Mayores y Termas Menores- han sido objeto de excavación desde el siglo XIX (De los Ríos, 1861), siendo varias las publicaciones a ellas referidas en el momento de iniciar nuestro proyecto de investigación (León, 1977-1978) publicaciones que se han visto incrementadas recientemente, vid infra.

13 Presedo y Caballos, 1985. Con posterioridad, vid infra.

14 Las termas de la calle Abades ya fueron notificadas por Rodrigo Caro en el siglo XVII quien las describió como Labyrinto de Sevilla (Caro, R. 1634: Adiciones al libro de las Antigüedades y Principado de Sevilla, Sevilla, cap III, 13 y ss.). Vid nota 33

15 Cabré, 1944; Beltrán, 1976.

16 Lostal, 1980; Beltrán Lloris et alii, 1987.

17 Almagro, 1951; Palahí y Vivó 1993. Vid infra.

18 Alvargonzález, 1903. Vid Infra.

19 Jordá, 1962. Con posterioridad, vid infra.

20 Luengo, 1956-61; Mañanes, 1983. Vid Infra.

21 García y Bellido, 1970 vid infra.

$22 \mathrm{El}$ primer edificio termal descubierto en Badalona, Hort
Durante los años setenta y ochenta el número de instalaciones termales hispanas excavadas se había incrementado de manera muy significativa respecto a las décadas precedentes, si bien este aumento numérico no tenía, para la mayor parte de los edificios, una correspondencia desde el punto de vista de la publicación de los resultados. Apenas existían trabajos monográficos basados en una metodología moderna y adecuada que permitieran un correcto conocimiento de los establecimientos termales. Tan sólo Baelo ${ }^{26}$, el conjunto republicano de Baetulo $^{27}$ o Conimbriga ${ }^{28}$, contaban con una rigurosa publicación. Este inicial "despegue" investigador en el campo de la arquitectura termal hispanorromana careció de una continuidad clara hasta finales de esta década, con la ejemplar publicación de los dos edificios de Mirobriga ${ }^{29} \mathrm{o}$ el compendio de las termas catalanas ${ }^{30}$ de inicios de los noventa dirigido por R. Mar, trabajos monográficos a los que cabe añadir las referencias, más o menos extensas, publicadas sobre otros complejos termales hispanos como Bilbilis, Tongobriga, Asturica Augusta, Bracara Augusta, Castulo, Clunia ${ }^{31}$ o Hispalis ${ }^{32}$. Mención aparte merecen los estudios de L. Roldán sobre Carteia

de les Monges, fue hallado por J. de C. Serra Ràfols en 1928 (Serra Ràfols, J. de C., 1928: Forma Conventus Tarraconensis I. Baetulo-Blanda, Barcelona 39-40) y puntualmente excavado por J. M. Cuyàs en 1947 , quien identificó los restos como parte de una instalación balnearia de carácter público en una breve y, hasta el momento, única publicación monográfica dedicada al conjunto (Cuyàs, 1947).

23 Pallarés, 1969 y 1975; Balil, 1960. Vid infra.

24 Termas del teatro. Almagro Basch, 1975.

25 Para todos ellos, vid infra.

26Étiènne y Mayet, 1971; interpretación posteriormente revisada por I. Nielsen (1990, I, 69). Con posterioridad a este momento vid infra.

27 Guitart, 1976; Guitart y Padrós, 1990. Más recientemente, vid infra.

28 Alarcâo y Étienne, 1977.

29 Biers, 1988.

30 En los que, por vez primera, se analizan de manera conjunta tanto los establecimientos termales de carácter público como los de ámbito doméstico, tanto urbano como rural. Mar, López y Piñol, 1993.

31 Vid Martín-Bueno y Liz, 1989; Tavares, 1986; Vidal Encinas, 1986; Gaspar et alii, 1986; Elvira, 1984 y Palol, 1984 respectivamente. Una recopilación bibliográfica de los principales trabajos dedicados a complejos termales hispanos hasta 1995 en Fernández Ochoa, Morillo, Zarzalejos y García-Entero, 1997.

$32 \mathrm{El}$ más antiguo de los edificios termales hispalenses, en la Cuesta del Rosario, es de época augustea y fue localizado por F. Collantes de Terán. El segundo complejo termal, de época adrianea, se encuentra en la calle Abades y está vinculado al Foro de las Corporaciones. Este complejo fue excavado por R. Corzo (Corzo, 1991). Vid también Blanco, A. 1979: Historia de Sevilla I (1). La Ciudad Antigua (De la prehistoria a los visigodos), Sevilla, esp. 133-135; Jiménez, A. 1985: Arquitectura de la Sevilla preislámica, Breve Historia de la Arquitectura de Sevilla, Sevilla; Campos Carrasco, J. 1993: La estructura urbana de la Colonia Iulia Romula Hispalis en época imperial, $A A C 4,181-219$, especialmente 202. 
e Italica $^{33}$, que ya contemplaban exhaustivamente los aspectos edilicios de las termas de estas dos ciudades, aunque sin abordar aún la interpretación funcional de los edificios ya publicados desde antiguo ${ }^{34}$.

Este panorama, brevemente descrito, carecía en el momento que iniciamos nuestro primer proyecto de trabajos de carácter general referidos a la península Ibérica. En este sentido debemos mencionar tan sólo el meritorio, aunque ya superado, inventario que G. Mora realizara en 1981 y en el que se recogían referencias de la totalidad de instalaciones termales entonces conocidas en Hispania ${ }^{35}$, trabajo que fue seguido en líneas generales por $\mathrm{H}$. Manderscheid en su catálogo bibliográfico recientemente actualiza$\mathrm{do}^{36}$. Posteriormente I. Nielsen dedicó, en su monografía sobre las termas del Imperio, algunas páginas a los conjuntos hispanos entonces conocidos dentro del capítulo de las provincias occidentales ${ }^{37}$. Por último y aunque no contempletaban de manera específica el caso hispano, publicaciones de carácter general como las de E. Brödner (1983), J. M. Degbomont (1984) y M. Fincker (1986), que siguen los trabajos clásicos de D. Krencker (1929) y F. Kretzschmer (1953), constituyeron una aportación inestimable para la interpretación de las características constructivas y la organización termal. En este sentido, cabe destacar el esfuerzo de síntesis llevado a cabo por F. Pérez Losada (1992) para los hipocaustos gallegos así como el de R. Sanz Gamo sobre el sistema de concamerationes en el área del sureste hispano $^{38}$.

\section{2.-OBJETIVOS Y METODOLOGÍA}

A la vista del estado de la cuestión reseñado, el objetivo primordial del primer proyecto de investigación fue la obtención de un corpus de datos amplio y representativo acerca de las técnicas constructivas en las termas de Hispania. A tal efecto, procedimos a catalogar todos los edificios termales del territorio peninsular, bien fueran rústicos o urbanos, públicos o privados, desde la época republicana hasta el Bajo Imperio con exclusión de las termas medicinales estudiadas por un equipo de la UNED bajo la dirección

33 Roldán Gómez, 1992, 1993.

34 Vid notas 13 y 14.

35 Mora, 1981.

36 Manderscheid, 1988 y 2004

37 Nielsen, 1990, I, 64-73, II 15-17 y 119-124

38 Sanz Gamo, 1987, 1987b, 1987c y 1989. En este mismo sentido debemos situar la publicación, más reciente, de de $\mathrm{M}^{\mathrm{a}} \mathrm{J}$. Pérex Agorreta ${ }^{39}$. Pero la tarea nos pareció que resultaría demasiado ambiciosa e inviable si se pretendía abordar el estudio e interpretación de todos los restos de termas higiénicas conservados. Por esta razón, nos impusimos una selección cuyo criterio consistió en el análisis de aquellos ambientes de las construcciones termales que han llegado hasta nosotros en mejores condiciones, esto es, los hypocausta o sistemas de calefacción. Nos planteamos, en primer lugar, que sería preciso averiguar si era posible asignar un tipo de hypocaustum concreto a parámetros temporales determinados. En segundo lugar, si resultaba factible el establecimiento de áreas geográficamente diferenciadas a partir de los sistemas constructivos adoptados. Un tercer punto a considerar era aquél que contemplara las diferencias estructurales de los hypocausta en relación con los caracteres específicos de los establecimientos termales, con el grado de romanización de una determinada área o, simplemente, con la cronología de los mismos. Finalmente, el volumen de información recogida podría, sin duda, arrojar luz de manera definitiva sobre el controvertido tema de la identificación de termas públicas y privadas, hasta el momento resuelta de forma sumaria en razón de su tamaño; asímismo, pretendíamos terminar de una vez por todas, con el socorrido binomio hypocaustum=termas, tan extendido en la bibliografía nacional y que parece olvidar el empleo de estas estructuras también como sistemas domésticos de calefacción.

Otros aspectos a considerar, al margen de los estrictamente arquitectónicos, eran los decorativos, como indicadores de una determinada cronología o nivel de romanización, junto con los urbanísticos que tienen en cuenta la situación del establecimiento termal, ya sea público o privado, dentro de la trama urbana. Pero estos aspectos de entidad y envergadura notable, se pospusieron de cara a ulteriores proyectos de investigación ${ }^{40}$.

La metodología de trabajo de este primer proyecto se enfocó hacia el análisis descriptivo de los materiales empleados en las edificaciones (tegulae, ladrillos, tubuli latericii, clavijas, tegulae mammatae, etc.) con vistas a establecer su representatividad, así como su posible función y la solución elegida en cada caso concreto. Además,
A. Torrecilla sobre las clavijas de doble pared (Torrecilla, 1999).

39 Termalismo Antiguo, Actas de la Mesa Redonda Aguas Medicinales, Termas curativas y culto a las aguas en la península Ibérica, (1991) Madrid, Espacio Tiempo y Forma Serie II, H.A. t. II, 5; Pérex Agorreta, 1997. 40 Vid infra. 
se recogieron los elementos arquitectónicos formales susceptibles de una clara ordenación y significativos para el establecimiento de cronología o de diferentes fases constructivas en los conjuntos analizados. La fórmula utilizada fue la elaboración de unas fichas-tipo integradas en una base de datos creada al efecto.

\section{3.- VALORACIÓN DE LOS PRIMEROS RESULTADOS}

La consecución de este primer proyecto de investigación conllevó la creación de un equipo de investigación sobre termas hispanas con sede en el Dpto. de Prehistoria y Arqueología de la $\mathrm{UAM}^{41}$.

Las primeras conclusiones derivadas de este primer proyecto han sido expuestas parcialmente en los trabajos publicados por el equipo en los últimos $\operatorname{años}^{42}$. Entre las conclusiones científicas más dignas de mención podríamos señalar las siguientes:

- En primer lugar, la imposibilidad de establecer diferencias apreciables en el empleo de material latericio en uno $u$ otro ambiente calefactado, salvo aquellos tipos característicos de determinadas estancias. Este sería, por ejemplo, el caso de los tepidaria, donde no suelen aparecer sistemas de concameratio.

- Tampoco parece sostenible la posibilidad de establecer criterios cronológicos fiables a partir de la aplicación de determinados tipos y modos de uso latericio en construcciones termales. La aparición de tegulae mammatae en determinadas habitaciones no implica necesariamente la antecedencia temporal de éstas respecto a otras que emplean tubuli en sus concamerationes. Tampoco se puede seguir manteniendo, a priori, el retraso cronológico de los hypocausta sostenidos mediante arquillos de aquellos realizados con pilae. Independientemente del momento en que se descubren determinadas soluciones estructurales, éstas conviven temporalmente incluso dentro de los mismos conjuntos.

- Por otra parte, la problemática particular que plantean los edificios termales, sometidos a continuas remodelaciones, dificulta extraordina-

$41 \mathrm{El}$ proyecto dirigido por C. Fernández Ochoa concitó el interés de un grupo de estudiantes del Tercer Ciclo y se formó un equipo de investigación compuesto por los profesores M. Zarzalejos y A. Morillo como investigadores del Proyecto, V. García-Entero como becaria de F.P.U., además de una serie de colaboradores como P. García Díaz y F. Gil Sendino. riamente el establecimiento de una relación directa entre cada fase constructiva y el empleo de determinados cánones latericios. Tan sólo hemos podido constatar que las dependencias de un conjunto que se realizan en un mismo momento emplean el mismo tipo de ladrillo y las mismas soluciones estructurales. Este sería el caso de los dos tepidarios y el caldario de las termas gijonesas, el conjunto calefactado de las habitaciones 5,6 y 7 de las Termas del Oeste de Mirobriga y la segunda fase constructiva de las termas de Bracara Augusta. En estos casos, la información latericia de los hipocaustos coincide con el diseño arquitectónico del edificio.

- Por lo que se refiere a la cronología relativa de los complejos termales conocidos, la información disponible se limita habitualmente a las fechas fundacionales y a los momentos de amortización funcional de las instalaciones y su reutilización con otros fines. Los edificios construidos en época tardorrepublicana se concentran en la costa tarraconense -Emporiae, Baetulo, Ca l'Arnau y Valentia- y el Valle del Ebro (Azaila) La Caboñeta (Burgo de Ebro, Zaragoza). La inmensa mayoría de los establecimientos hispanos arrancan de finales del siglo I d. C. y primera mitad del siglo II d. C. El abandono y cambio de vocación funcional de estas instalaciones tiene lugar desde finales del III d.C. el fin de la siguiente centuria. En este sentido, las termas no constituyen una excepción dentro de la particular evolución histórica y urbanística de la Hispania romana.

- Otra anotación de interés cabría hacer con respecto a las marcas de fábrica halladas en los ladrillos de las termas hispanas. Si en ocasiones se ha realizado una lectura cronológica de este indicio, hoy día todos los autores matizan el dato en función de otras observaciones (posibles reutilizaciones de latericio sellado en ciertas construcciones, por ejemplo). En Hispania, los casos paradigmáticos de latericio sellado se encuentran en edificios de la Bética.

Al hilo de los argumentos que hemos venido manejando, cabría plantearse la posibilidad de establecer diferencias regionales en cuanto a la preferencia por determinados tipos o usos latericios. El estado actual de la investigación no lo

42 Varias son las publicaciones que los miembros del equipo de investigación dedicamos al análisis de las características constructivas de las termas hispanas, tanto de ámbito público como privado. Vid Arribas, 1999; Fernández Ochoa y Zarzalejos, 1996; Fernández Ochoa, Morillo y Zarzalejos, 1999; García-Entero, 1997 y $2001 b$. 
permite. Esta regionalización podría tal vez ser factible considerando la información derivada de los proyectos arquitectónicos concretos, pero nunca del mero análisis del material latericio. De la misma manera, mientras no avance nuestro conocimiento sobre las instalaciones industriales destinadas a la fabricación de materiales de construcción, no podremos pronunciarnos con cierta seguridad acerca de una cuestión tan interesante como las fuentes de aprovisionamiento de lateres para conjuntos termales. El abastecimiento local parece ser la vía más lógica para cubrir esta demanda.

Llegados a este punto, es necesario plantear una última consideración de tipo global: a pesar de la libre interpretación de los elementos constructivos (tipo y dimensiones de los ladrillos, revestimiento de la cámara de calor, modalidad de pilae y de concamerationes...) se mantiene una fidelidad genérica en la estructura de funcionamiento de las termas difundida por los escritores latinos. Esta uniformidad funcional no es sino una manifestación más de la capacidad de Roma para difundir formas culturales propias hacia todas las tierras del Imperio.

2.- LA CONSOLIDACIÓN DEL PROYECTO: ARQUITECTURA Y ANÁLISIS FUNCIONAL DE LAS TERMAS HISPANORROMANAS.

Tras la fase de estudio precedente, nos pareció estar en condiciones de abordar la continuidad del proyecto con el fin de elaborar un análisis integral de las estructuras arquitectónicas y de la disposición funcional de los distintos ambientes termales, así como de su inserción en el tejido urbano. Por ello, en 1996, contando con el mismo equipo de trabajo ${ }^{43}$, ofrecimos un nuevo proyecto a la DGICyT (PS95-0043) que fue aprobado bajo el título Termas romanas en Hispania: Arquitectura y análisis funcional y que se desarrolló hasta fines de 1999 tambien en el seno del Dpto. de Prehistoria y Arqueología de la UAM.

\section{1.- EsTADO DE LA CUESTIÓN.}

El estado de la cuestión que hemos reflejado de modo sumario más arriba, mostraban una tendencia favorable en el estudio de los conjuntos termales hispanos a lo largo de las dos últimas décadas, si bien, salvo excepciones, los trabajos

\section{Vid nota 41}

44 García Marcos, 1994.

45 Fernández Ochoa, 1995; Fernández Ochoa y Zarzalejos, 1996. Más recientemente Fernández Ochoa y García Díaz, 2000 y Fernández Ochoa, 2002. adolecían de graves deficiencias en la interpretación de los edificios, con errores en la identificación de las estancias, descripciones incompletas o imprecisiones en la determinación de las fases constructivas. Además, se hacían evidentes los reparos a la hora de establecer hipótesis sobre las soluciones arquitectónicas de las partes colapsadas, olvidando que un cuidadoso estudio de la planta y articulación de los distintos elementos arquitectónicos, podría permitir la elaboración de propuestas coherentes acerca de la volumetría del edificio.

\subsection{OBjetivos Y METODOLOGÍA.}

Para llevar a cabo esta segunda fase en el Proyecto Termas Romanas elaboramos una completa y compleja base de datos (File Maker) que contemplaba todos los aspectos técnicos, edilicios, funcionales, tipológicos, decorativos, fotográficos y planimétricos de cada uno de los ambientes documentados en las termas públicas y privadas conocidas en Hispania. Lógicamente, la realización de esta base de datos conllevó no sólo un arduo trabajo bibliográfico, en parte ya realizado durante el proyecto precedente y que se vio ahora completado al calor de las diferentes publicaciones que veían la luz, sino también una completa tarea de campo destinada a seleccionar aquellas instalaciones termales, públicas y privadas de ámbitos urbano, suburbano y rural, y cuyo estado de conservación permitía apuntar y solucionar cuestiones de carácter planimétrico, constructivo y cronológico.

Como apuntamos, el segundo lustro de la década de los noventa supuso, al socaire de las dos espléndidas monografías de I. Nielsen y F. Yegül anteriormente citadas, el verdadero despegue en la investigación sobre las instalaciones termales hispanorromanas. Este impulso se vio reforzado, en gran medida, por el incremento constante de las intervenciones urbanas que posibilitó, no sólo la ampliación considerable de la nómina de los edificios de nuestro catálogo, sino también de los datos obtenidos en la excavación de cada uno de ellos.

En este sentido, las publicaciones de conjuntos como Asturica Augusta ${ }^{44}$, Gijón ${ }^{45}$, Bracara Augusta ${ }^{46}$, Labitolosa ${ }^{47}$ o, en la esfera "privada", Cercadilla ${ }^{48}$, ya proporcionaban numerosos datos y preludia-

46 Martins et alii, 1994.

47 Magallón et alii, 1994; Magallón et alii, 1995; Magallón et alii, 1995b; Magallón et alii, 1997; Sillières et alii, 1995; Sillières et alii, 2000.

48 Hidalgo, 1996 y $1996 \mathrm{~b}$. 
ban una interpretación más minuciosa de los mismos. Esta situación afortunadamente se viene cumpliendo para los edificios termales recientemente excavados y analizados como los de Valentia $^{49}$, La Caboñeta, Ca l'Arnau ${ }^{50}$, Edeta Liria $^{51}$, el de la ciudad romana de Emporiae ${ }^{52}$ o Tongobriga ${ }^{53}$, entre otros (vid infra). Algo semejante cabe esperar de los conjuntos todavía parcialmente conocidos de Carthagonova $a^{54}$, Caesaraugusta $^{55}$, Hispalis $^{56}$, Segobriga ${ }^{57}$, Complutum ${ }^{58}$, Malaca $^{59}$, Lucentum $^{60}$, Tarraco ${ }^{67}$ o Corduba ${ }^{62}$; en estos dos últimos casos, apenas intuidos en los años precedentes. Este periodo que podríamos fijar entre 1995 y 2000, proporcionó nuevas obras de síntesis sobre los edificios termales de alguna provincia o ciudades concretas de nuestra península, caso del trabajo de L. Roldán sobre las termas de la Betica $^{63}$, la recopilación de las termas cordobesas $^{64}$ o el de T. Barrientos ${ }^{65}$ sobre los edificios balnearios de la capital lusitana, trabajos que, junto al ya publicado sobre los complejos catalanes $^{66}$ y los que iban apareciendo fruto de nuestra propia investigación ${ }^{67}$, permitían contar con una sólida base comparativa en la que se incluían también las instalaciones de carácter doméstico $^{68}$ que habían quedado, ciertamente, relegadas a un segundo plano por la investigación precedente.

La metodología aplicada en el nuevo proyecto suponía añadir a la información disponible sobre los hipocaustos, los datos referidos al resto de los ambientes termales no calefactados (frigidaria, apodyteria, palestras, etc..), sistemas de

49 Escrivà y Ribera, 1993; Ribera, 1998; Marín y Ribera, 1999; Nolla, 2000.

50 Martín, 1998-1999 y 2000.

51 Escrivà, Martínez Camps Vidal Ferrús, 2001.

52 Vid nota 17. Con posterioridad a estas publicaciones, otros trabajos han analizado las termas de la neapolis ampuritana (Palahí y Vivó, 1995; Sanmartí, 2000). Por su parte, las termas de la ciudad romana, todavía en proceso de excavación, han sido objeto de una reciente publicación, vid Aquilué, Castanyer, Santos y Tremoleda, 2002.

53 Tavares, 1997.

54 Ramallo, 1989-1990; Ramallo y Ros Sala, 1993, 258.

55 En esta ciudad conocemos el complejo termal de la calle San Juan y San Pedro excavadas por C. Aguarod y habilitadas recientemente como museo. A la espera de su publicación monográfica vid Aguarod, C. y Mostalac, A. 1998: La Arqueología de Zaragoza en la Antigüedad tardía, Historia de Zaragoza 4, Zaragoza, 25-26 y Aguarod, C. 1999: Museo de las termas públicas de Caesaraugusta, folleto explicativo, Zaragoza.

56 Vid nota 32.

57 Abascal et alii, 1997; Almagro-Gorbea, M. y Abascal, J. M., 1999: Segobriga y su conjunto monumental, Madrid.

58 Rascón, 1995. abastecimiento de agua y saneamiento así como soluciones constructivas de distinta índole. En definitiva, el objetivo primordial del segundo proyecto era la interpretación completa de las Thermae y Balnea hispanos, prestándose una especial atención a las instalaciones de carácter doméstico. Dentro de este objetivo, se incluyó lógicamente la definición de las plantas, alzados y cubiertas, organización interna del edificio, sucesión de ambientes, así como la morfología y evolución de cada una de las estancias termales. Todos estos aspectos permitirían concluir si es o no posible asignar un modelo de edificio o de estancia concreta a zonas geográficas o períodos temporales determinados. Del mismo modo, se trataba de establecer la secuencia temporal de implantación de ciertos tipos termales y la posibilidad de identificar "familias" de edificios a partir de referentes concretos.

\subsection{VALORACIÓN DE LOS RESULTADOS.}

Las mejoras que se venían produciendo en el registro arqueológico de los edificios nuevamente excavados o analizados por vez primera, permitían concretar, en cierta medida, sus cronologías, hecho que ha supuesto un gran avance en el conocimiento de la propia evolución arquitectónica de las termas hispanas.

En este sentido, e inmersa en esta favorable dinámica de la investigación termal hispanorromana, hemos de situar la revisión de edificios
59 Rodríguez Oliva, 1993; Fernández Rodríguez et alii, 2001.

60 Olcina y Pérez, 1998.

61 Díaz, García y Macías, 2000 y 2000b; Díaz y Macías, 2004..

$62 \mathrm{Al}$ margen de los hallazgos y noticias sobre diversos complejos termales cordobeses conocidos desde los años veinte del pasado siglo y recopilados recientemente por A. Ventura (1997), destacamos la reciente excavación de la calle Concepción que ha permitido conocer un sector de uno de los complejos termales públicos de esta ciudad. Vid. Vaquerizo Gil, D. (Dir.), 2003: Guía Arqueológica de Córdoba. Una visión de Córdoba en el tiempo a través de su patrimonio arqueológico, Córdoba, 53-55.

63 Roldán, 1996.

64 Ventura 1997.

65 Barrientos, 1997

66 Vid nota 30.

67 Tanto de carácter general para el conjunto de la Península -vid Fernández Ochoa et alii, 1997- como para sectores concretos de la misma, principalmente el Noroeste, Fernández Ochoa y García-Entero, 1999.

68 García-Entero, 1997, 1997b, 1999, 2001, García-Entero y Arribas, 2000. 
conocidos de antiguo que han resultado, durante estos últimos años re-excavados, reinterpretados o, cuando menos, puntualizados en algunos de sus aspectos. Así, debemos hacer alusión a los trabajos aparecidos sobre las instalaciones termales de Italica $^{69}$, $_{\text {Carteia }}{ }^{70}$, Baelo $^{71}$, el conjunto republicano de Emporiae ${ }^{72}$, Asturica Augusta ${ }^{73}$, Lancia $^{74}$, Bilbilis $^{75}$, Bracara Augusta ${ }^{76}$, Conimbriga ${ }^{77}$, el edificio republicano de Baetulo $^{78}$ o los complejos de Barcino $^{79}$. Sin embargo, la arqueología termal hispana no sólo se ha visto enriquecida por las revisiones de antiguos edificios sino, principalmente, por la aparición y excavación sistemática de nuevos complejos, algunos ya aludidos, basadas en una mayor rigurosidad en el registro estratrigráfico. Nos referimos a las termas de Ilerda $a^{80}$, La caboñeta, Ca l'Arnau ${ }^{81}$, la Emporiae romana ${ }^{82}$, Tarraco $^{83}$, Edeta-Liria ${ }^{84}$, Valentia ${ }^{85}, \quad$ Illici $^{86}$, Labitolosa $^{87}$, las termas del Foro de Segobriga ${ }^{88}$, Complutum $^{89}$, Tongobriga ${ }^{90}$, Gijón ${ }^{91}$, San Juan de Maliaño $^{92}$, Corduba ${ }^{93}$ o Astigi $^{94}$.

Las constantes novedades surgidas en el terreno de la arquitectura termal nos impulsaron a convocar un Coloquio Internacional en el que tuvieran cabida las últimas investigaciones sobre estos edificios en el Occidente del Imperio y donde se pudieran poner en común la problemática, planteamientos y líneas de investigación inherentes a las instalaciones balnearias. Esta reunión se llevó a cabo en Gijón en diciembre de 1999 y sus resultados vieron pronto la luz ${ }^{95}$. En este encuentro se fijaron los puntos de referencia

69 Stephan, 1996; Roldán, 1996.

70 Roldán, 1996.

71 Silliéres, 1995; Roldán, 1996.

72 Vid nota 52.

73 García Marcos y Burón 2000; Sevillano y Vidal, 2000 y 2002.

74 Liz, Celis y Gutiérrez, 2000; Celis, Gutiérrez y Liz, 2002. 75 Guiral y Martín-Bueno, 1996; Martín-Bueno y Liz, 1999. 76 Martins y Silva, 2000.

77 Correia y Reis, 2000; Reis, 2004.

78 Comas et alii, 2000.

79 Miró y Puig, 2000; trabajo de reestudio y reinterpretación de los resultados de las antiguas excavaciones que, unidos a los aportados por las nuevas intervenciones arqueológicas llevadas a cabo en Barcino, permiten ir vislumbrando la situación, características y evolución de las instalaciones termales de la ciudad.

80 Payà et alii, 1996; Payà i Mercè, 2000; Gil et alii, 2001.

81 Vid nota 50.

82 Vid nota 52.

83 Vid nota 61.

84 Vid nota 51.

85 Vid nota 49.

86 Ramos y Tendero, 2000.

87 Vid nota 47.

88 Vid nota 57. básicos para el conocimiento arqueológico e histórico de los momentos de implantación de los sistemas termales en el ámbito occidental del Imperio y, particularmente, en Hispania.

Entre las aportaciones principales surgidas de este Coloquio y que vinieron a reforzar las conclusiones parciales establecidas a partir de edificios concretos, cabe destacar la identificación de, al menos, dos grandes generaciones de termas públicas en Hispania a las que es posible asignar tipologías arquitectónicas concretas ${ }^{96}$. Sin duda, las más recientes excavaciones de Ca l'Arnau, La Caboñeta y Valentia, llevadas a cabo con rigurosos métodos estratigráficos, han confirmado la existencia de unas pautas arquitectónicas y funcionales ya percibidas en otros conjuntos termales de época republicana conocidos con anterioridad -Baetulo, Emporiae, Segobriga y, quizás, Azaila y Arcobriga $a^{97}$. Estas características tipológicas se corresponden con una primera generación de instalaciones termales de la Península ibéri$\mathrm{ca}^{98}$, de marcada precocidad respecto al resto del arco mediterráneo dado que su implantación puede situarse hacia mediados del II a.C.

Esta primera generación de instalaciones termales, de gran eficacia y larga tradición de uso ${ }^{99}$, se vio reemplazada, desde época augustea, por una nueva tipología de edificios surgida en ámbito campano y ampliamente difundida en la totalidad del Imperio, generalizándose su presencia en Hispania en época flavia. Se trata del modelo lineal que, con todas sus variantes (lineal simple,

89 Vid nota 58.

90 Vid nota 53.

91 Vid nota 45.

92 Muñoz, Morlote y Montes, 2000.

93 Vid nota 62.

94 Romo et alii, 2001; Romo, 2002.

95 Fernández Ochoa y García-Entero, 2000.

96 Tipología creada a partir de la sistematización realizada en 1929 a raíz del estudio del edificio de Tréveris (Krencker et alii, 1929) y que, aunque siempre sujeta a numerosas variantes, dado que no existieron dos instalaciones termales iguales, permite establecer los parámetros constructivos presentes en las distintas épocas. Ver al respecto lo expuesto en Fernández Ochoa y García-Entero, 1999; Fernández Ochoa, Morillo y Zarzalejos, 2000.

97 A los que quizás haya que sumar en un futuro próximo el edificio de Malaca. Vid nota 59.

98 Al margen de los trabajos monográficos suscitados por cada uno de estos edificios (vid supra), J. M ${ }^{\mathrm{a}}$ Nolla estableció en el Coloquio de Gijón los parámetros comunes que guían la edificación de estos complejos republicanos y que, configuran, en el estado actual de la investigación, el grupo de edificios mejor conocido de todo el Mediterráneo (Nolla, 2000).

99 Nolla, 2000, 58. 
lineal angular, semisimétrico), constituye el más simple de los sistematizados en su día por Krencker y al que es posible asignar buena parte de las termas hasta ahora conocidas en nuestra península $^{100}$. Sobre este tipo básico se produce, a mediados del siglo I d.C., una complejización constructiva que conlleva, entre otros elementos, un recorrido anular del bañista; modelo que, sin embargo, no se difundirá en Hispania hasta los siglos II y III d.C. ${ }^{101}$

Al margen de la implantación y evolución atestiguadas del modelo campano, el surgimiento y desarrollo del modelo imperial desde época neroniana, basado en la duplicación a partir de un eje de los ambientes termales, parece tener escasa repercusión entre los edificios hispanos. En el estado actual de la investigación, apenas el edificio de Los Arcos I de Clunia, hasta hace pocos años verdadero unicum de este modelo, y, quizás, las termas portuarias de Tarraco $^{102}$ pueden ser englobados bajo este epígrafe, si bien cabe esperar los resultados de las excavaciones desarrolladas en la ciudad de Emerita.

Sin embargo, la monumentalidad de los edificios hispanos parece configurarse a partir de la evolución del modelo campano antes señalado y que permite construir edificios de plan semisimétrico con duplicidad de algunos ambientes termales. La adopción del plan semisimétrico presente en las termas flavio-trajaneas de Conimbriga, en Mirobriga o en Carteia, vendría a ser en Hispania el reflejo de los modelos termales de mayor envergadura implantados en la propia Roma y en otras grandes ciudades del orbe romano a partir del siglo II d.C.

Como ya hemos apuntado, en los planteamientos iniciales del segundo proyecto se incluía de manera muy significativa el estudio de los edificios de carácter doméstico, tanto de ámbito urbano como rural, que adolecían de un marcado abandono por parte de la investigación arqueológica $^{103}$. A ellos dedicamos una de nosotras nuestra Memoria de Licenciatura ${ }^{104}$ y Tesis Doctoral $^{105}$, al margen de trabajos puntuales sobre edificios concretos ${ }^{106}$ o sectores peninsulares $^{107}$. Estas investigaciones han permitido analizar la totalidad de los balnea hasta ahora conoci- dos en Hispania en función de los mismos parámetros planteados para el estudio de las instalaciones de carácter público, esto es, atendiendo a sus características arquitectónicas, tipológicas, morfológicas, decorativas y cronológicas. Conocemos el ritmo de implantación de los baños domésticos en la península Ibérica, pudiéndose observar cómo las primeras instalaciones hacen su aparición ya desde las décadas finales del siglo II a.C., siendo fruto de la presencia misma de un contingente poblacional de origen itálico en suelo peninsular. La evolución tipológica atestiguada en las instalaciones hispanorromanas desde este momento hasta la generalización del fenómeno balneario doméstico a lo largo del siglo I d.C. va pareja a la acontecida en la propia península itálica, reforzándose la importancia de estos edificios en la arquitectura doméstica aristocrática a partir del siglo III d.C., momento en el que los balnea de ámbito rural adquirieron, como lugar de encuentro social que sustituyó a los grandes complejos públicos, un marcado carácter propagandístico del estatus social de su propietario, circunstancia común a los balnea de otras áreas del Imperio ${ }^{108}$.

La conclusión de estos trabajos, culminó con la creación de una serie termal dentro de las Monografías de Arquitectura Romana de la UAM y en la que, hasta el momento, ha visto la luz su primer volumen ${ }^{109}$.

\section{3.- LA BÚSQUEDA DE UN ESTUDIO INTE- GRAL DE LAS TERMAS HISPANORROMANAS.}

El tramo final del plan de investigación se desarrolló entre diciembre de 2000 y 2003 con un nuevo proyecto (DGICyT BHA2000-0202) en el que abordamos el estudio de la decoración de las termas hispanorromanas con el título de La imagen de las termas romanas en Hispania: Programas decorativos y ambiente interior.

\subsection{ESTAdo de LA CUESTIÓN.}

Frente al renovador impulso acaecido en los últimos años en el conocimiento de la arquitectura termal, apreciamos a lo largo de nuestra
100 Fernández Ochoa y García-Entero, 1999; Fernández Ochoa, Morillo y Zarzalejos, 2000.

101 Vid nota anterior.

102 Vid nota 61.

103 Sobre el estado de la investigación del tema con anterioridad a nuestros trabajos, véase lo expuesto en Fernández Ochoa et alii, 1997 y García-Entero, 2001, 21-26.
104 García-Entero, 1997 y 2001.

105 García- Entero, 2003 y 2006

106 García-Entero, 1997b, 2004 y 2005 e.p.

107 Fernández Ochoa y García-Entero, 1999; GarcíaEntero, 1999.

108 García-Entero y Arribas, 2000 con bibliografía. 109 García-Entero, 2001. 
investigación una más que evidente laguna respecto a los programas decorativos que fueron incorporados a tan importantes instalaciones. Por otra parte, el panorama investigador fuera de nuestras fronteras mostraba una orientación preferente hacia el estudio de los desarrollos ornamentales de las grandes termas imperiales, quedando en un segundo plano los dedicados a los balnea de carácter privado y los de ámbito doméstico.

Si la tradición de los trabajos sobre arquitectura termal arranca, como hemos apuntado líneas arriba, de manera significativa a partir del primer tercio del siglo $\mathrm{XX}^{110}$ y continúa de forma vertiginosa hasta nuestros días, la investigación dedicada a los programas decorativos desarrollados en las instalaciones balnearias acusa un considerable retraso. Sin duda, las propias circunstancias en las que han llegado hasta nosotros los edificios termales, de los cuales en la mayoría de los casos tan sólo conocemos las trazas básicas de sus plantas, justifica en parte este vacío en la investigación. Por otro lado, los restos decorativos documentados se han analizado desde una perspectiva artística sin tener en consideración que dichos vestigios formaron parte de programas ornamentales estrechamente vinculados a las trazas arquitectónicas del edificio. Tan solo en los últimos años se ha ido abriendo paso entre los investigadores la necesidad de abordar el estudio integrado de todos los restos que nos ofrece una reconstrucción real del ambiente interior e imagen que recibirían los bañistas cuando frecuentaban los edificios termales.

Los pavimentos musivos constituyen, sin lugar a dudas, el objeto principal de análisis por parte de los estudiosos dedicados a la decoración de las instalaciones termales, tanto públicas

110 Vid nota 4.

111 Entre los trabajos más significativos cabe destacar los de Aurigemma, S. 1961: Mosaici da Casal di tatua e da Risaro, Bollettino d Arte 46, 150-158; Clarke, J. R. 1982: The origins of black-and-white figural mosaics in the region destroyed by Vesuvius, La regione sotterrata dal Vesuvio: Atti del convegno internazionale, Napoli; Id. 1992: Mosaic workshops at Pompeii and Ostia Antica, 5th International Colloquium on Ancient Mosaics (Bath, 1987), J.R.A. Supp.series 9, 89-102; Id 1990: Neptune and his quadriga: the diffusion of a motif in the black and white mosaics of Italy, VI Coloquio Internacional sobre Mosaico Antiguo, Palencia-Mérida, pp. 309-316; Depuma, R. D. 1969: The roman fish mosaic, Michigan; Dunbabin, 1989; Id.1990: Ipsa deae vestigia... Footprints divine and human on Graecoroman monuments, J.R.A. 3, 85-109; Levi, D. 1947: Antioch Mosaics Pavements, Princeton; Mino, M. R. 1975: como privadas. La península Itálica, en especial la zona vesubiana y la ciudad de Ostia Antica han sido, por la excepcional conservación de sus restos, las que han centrado la atención de los investigadores ${ }^{111}$. Por su parte, el trabajo de $\mathrm{H}$. Manderscheid es, hoy por hoy, el catálogo más completo sobre esculturas asociadas a los grandes complejos termales de carácter imperial ${ }^{112}$. Respecto a la pintura mural, varios son los trabajos dedicados a la decoración de las instalaciones balnearias entre los que cabe destacar el de $\mathrm{H}$. Mielsch, los de L. Jacobelli y O. Leblanc y A. Lebot-Helly ${ }^{113}$ entre otros.

Los estudios de los elementos decorativos asociados con estancias termales hispanas adolecen principalmente de la parcialidad con la que se han acometido, de modo que para tener una idea global es obligado consultar decenas de publicaciones de calidad muy heterogénea. Al mismo tiempo, en la mayor parte de los casos, estos análisis puntuales, principalmente dedicados a los pavimentos musivos, han sido realizados al margen de las características de los edificios a los que pertenecieron. Atendiendo a los mosaicos y aparte del Corpus de Mosaicos de Hispania coordinado por J. $\mathrm{M}^{\mathrm{a}}$ Blázquez en el que se vienen recogiendo y analizando todos los pavimentos musivos conocidos en Hispania, debemos destacar otros estudios de carácter general o regional de gran importancia en los que de manera puntual se hace alusión a algunos pavimentos de los complejos termales hispanos como son los de X. Barral ${ }^{114}, \mathrm{M}$. Guardia ${ }^{115}$, D. Fernández-Galiano $^{116}$ y S. Ramallo Asensio ${ }^{117}$. Asímismo existen algunos trabajos dedicados a pavimentos musivos de gran significación como los realizados sobre el mosaico de las termas de la villa de La Pineda o de la Casa de Neptuno de Italica $^{118}$. De especial importancia por su relación

Un Mosaico a soggetto marino dalla villa rustica di Riaro, Bollettino dArte 60, 103-104; Stern, H. 1959: Origine et debuts de la mosaïque murale, Annales de tEst 22; Ben Abed Ben Khader, A. 1994: Les mosaïques de la Maison du Peristyle figuré et de ses thermes à Pupput (Hammamet), Johnson, P., Ling, R. y Smith, D. J. (ed).: Fifth International colloquium on ancient mosaics, JRA Suppl. series 9-1, 173-186.

112 Manderscheid, 1981.

113 Mielsch, 1975; Jacobelli, 1987; 1988 y 1995; Leblanc y Lebot-Helly, 1997.

114 Barral, 1978.

115 Guardia, 1992.

116 Fernández-Galiano, 1987.

117 Ramallo Asensio, 1985.

118 Bobadilla, 1969; Balil y Mondelo, 1985; Blanco y Luzón, 1974.

119 Neira Jiménez, 1992 y 1997. 
con los ambientes balnearios son las publicaciones de L. Neira ${ }^{119}$.

Por lo que respecta a la decoración pictórica y al margen del ya clásico trabajo de L. Abad en el que se recogen referencias concretas a las características de los programas decorativos de las salas termales entonces conocidas en España ${ }^{120}$, hemos de destacar, sin duda, los estudios realizados en los últimos años por uno de los miembros de nuestro proyecto, C. Guiral ${ }^{121}$.

En lo que concierne a los aspectos escultóricos, varias son las piezas claramente asociadas en Hispania a los ambientes termales, siendo significativa la escasez de esculturas relevantes vinculadas con los edificios de carácter público, circunstancia, no obstante, cambiante gracias a las más recientes intervenciones arqueológicas ${ }^{122}$ o a las revisiones efectuadas sobre piezas ya conocidas de antiguo ${ }^{123}$. Destaca, sin duda, el reciente trabajo de E. M $\mathrm{M}^{\mathrm{a}}$ Koppel dedicado exclusivamente a la decoración escultórica de las termas hispanas ${ }^{124}$. Paradójicamente son los grupos escultóricos asociados a balnea domésticos rurales los mejor conocidos hasta el momento en nuestra península y de los que se han ocupado diversos trabajos en los últimos años ${ }^{125}$ y entre los que cabe destacar el grupo escultórico de la villa tarraconense de Els Munts ${ }^{126}$.

\subsection{OBjeTIVOS Y MeTODOLOGÍA.}

El objetivo primordial del tercer y último proyecto sobre Termas Romanas en Hispania era la realización de un catálogo completo y actualizado de los programas decorativos asociados a las instalaciones termales, tanto de carácter público como privado y doméstico de la península Ibérica. Para ello nos propusimos analizar las características de los motivos y programas iconográficos y ornamentales realizados tanto sobre pavimentos como sobre revestimientos parietales y grupos escultóricos de modo que se pudieran aclarar y matizar cuestiones de carácter cronológico y puntualizar, en la medida de lo posible, la finalidad de alguna sala termal, de tal forma que pudiéramos definir de manera más clara los pla-

120 Abad, 1982.

121 Guiral y Martín-Bueno, 1996; Guiral, 2000.

122 En este sentido cabe destacar, sin duda, el importante grupo escultórico hallado en las termas de Astigi (Écija, Sevilla), Romo et alii; 2001; Romo, 2002.

123 Baste de ejemplo la Venus de Illici que, localizada en 1929 , puede ser vinculada con alguno de los edificios termales de la ciudad. Noguera, 2002.

124 Koppel, 2004. nes de uso de las termas hispanorromanas. Sin duda, la resolución de estas cuestiones nos permitiría establecer el modo en el que los responsables de la erección de tales instalaciones adoptaron y adaptaron los modelos y temática surgidos en la península Itálica, así como esclarecer cuestiones acerca de la existencia de talleres locales, itinerantes etc. y afinar en el reconocimiento de la evolución de los gustos ornamentales a lo largo de varias centurias (siglos II a.C.-V d.C.).

Para ello contábamos con la base de datos creada para el primer proyecto y en la que se han ido actualizando todos los datos referentes a los elementos decorativos conservados o conocidos por noticias de cada uno de los ambientes termales de todas las termas catalogadas. Este trabajo se halla todavía en fase de realización, que pretendemos concluir en breve, y que verá la luz en forma de monografía sobre las instalaciones termales de carácter público en Hispania.

\subsection{VALORACIÓN DE LOS RESULTADOS.}

Pese a que el estudio no ha finalizado aún en toda su extensión, podemos adelantar algunas conclusiones extraídas del análisis de los complejos domésticos que permiten establecer una serie de pautas que guían los rasgos ornamentales de estos edificios ${ }^{127}$ y que son coincidentes con lo expuesto para los complejos domésticos cam$\operatorname{panos}^{128} \mathrm{y}$, en líneas generales, también para los complejos termales de carácter público ${ }^{129}$.

Desde el siglo II y mayoritariamente, a partir del siglo III, estas edificaciones se contagiaron de la tónica general de enriquecimiento que afectó al conjunto de dependencias de las viviendas urbanas y rurales. Desde el punto de vista decorativo, observamos cierta tendencia hacia la adecuación de la temática ornamental y la funcionalidad de las salas, repitiéndose la presencia de unos temas recurrentes relacionados con el mundo marino y sus divinidades, el deporte -con escenas de pugilato- y elementos vinculados con la propia práctica del baño -el ajuar con la presencia de sandalias, ungüentarios, estrígiles, etc.., temas que estuvieron presentes en los ambientes
$125 \mathrm{Al}$ grupo de Balazote ha dedicado J. M. Noguera varios trabajos (Noguera, 1994 y 1995). De este mismo autor es el estudio de la escultura Diana procedente de las termas de la Casa de Hippolytus de Complutum (Noguera, e.p.).

126 Berges, 1970; Koppel, 1993, 1995, 1998 y 2000.

127 Vid García-Entero, 2003 y 2006

128 Haan, 1993.

129 Guiral, 2000. 
termales tanto en pintura mural como en mosaicos parietales o pavimentos musivos. La presencia de divinidades y fauna marinas en las piscinas, alvei y natationes de estos edificios, debían aportar al bañista, gracias al efecto producido por la presencia de agua, la sensación de zambullirse en el propio océano, del mismo modo que la recreación de escenas de palestra, temática muy bien adaptada a estas salas balnearias, debía constituir un elemento importante para la ambientación del usuario de las termas. No obstante, esta vinculación temática, cuando están presentes divinidades de las aguas, pudo igualmente responder a motivaciones de carácter profiláctico, máxime si tenemos en cuenta los peligros que pudieron acechar al bañista que frecuentaba, principalmente, los complejos públi$\cos ^{130}$.

Son los frigidaria las salas que más información aportan sobre sus características ornamentales, en parte porque su conservación ha sido siempre mejor que la de las salas calefactadas muchas de ellas desposeídas de su material latericio- y en parte, porque fueron estas dependencias frías las que reunieron los mayores esfuerzos de los propietarios por manifestar su riqueza y poder.

Sin embargo, a pesar de la relativa frecuencia de los temas mencionados, la decoración más habitual de los balnea domésticos hispanorromanos fue el uso de revestimientos marmóreos, pintura mural -de la que apenas conocemos sus motivos-, mosaicos de elementos geométricos y florales y, entre los complejos más modestos, el simple recubrimiento de las superficies mediante opus signinum.

El estudio de las evidencias decorativas de las termas hispanorromanas nos ha conducido al planteamiento de un problema de primera magnitud como es el de la reutilización y reocupación de las instalaciones termales, edificaciones que no sólo mantuvieron un largo funcionamiento sino que, por su configuración arquitectónica y solidez constructiva, favorecieron, una vez abandonados $\mathrm{u}$ obliterados, su reutilización y amortización para fines diversos a los originales ${ }^{131}$, fenómeno, por otra parte, al que cada vez se presta mayor atención ${ }^{132}$.

De todo lo hasta aquí expuesto, creemos

130 Dunbabin, 1989.

131 Fernández Ochoa y Zarzalejos, 2001; García - Entero, 2005 e.p. y 2006

132 Ward-Perkins, 1984, 127 y ss., Chavarría, 1996, 1997 y 1998; Peña Cervantes, 2000; Fuentes Domínguez, poder concluir que el estado de la investigación sobre los complejos termales hispanos ha experimentado un auténtico vuelco en la última década, en parte gestado al calor de la propia dinámica de estudio sobre estos edificios generada en todo el occidente romano, pero también, pensamos modestamente, que potenciado por los proyectos de investigación que hemos desarrollado en el Dpto. de Prehistoria y Arqueología de la Universidad Autónoma de Madrid. De este modo, si al iniciar nuestro primer proyecto de investigación en el año 1993, la península Ibérica mostraba un significativo vacío en lo referente a las instalaciones balnearias romanas, podemos afirmar que, a la fecha de redacción de este balance ${ }^{133}$, es Hispania en su conjunto, probablemente, una de las provincias romanas donde actualmente se conoce mejor este tipo de construcciones tanto en el ámbito público como en el privado.

\section{Bibliografía:}

AAVV, (1991): Les Thermes Romains, Actes de la table ronde organisée par l'École française de Rome (1988), CEFR 142, Roma.

AAVV, (1993): Terme romane e vita quotidiana, Módena.

AAVV, (2002): Espacios de ocio, convivencia y cultura en el Arco Atántico. Los Baños públicos como símbolo de romanidad, Oviedo.

ABAD, L. (1982): La Pintura Romana en España, Madrid.

ABASCAL, J. M., ALMAGRO GORBEA, M. Y LORRIO, A., (1997): "Las Termas monumentales de Segobriga”, Revista de Arqueología 195, 38-45.

ALMAGRO, M. (1951): Ampurias, historia de la ciudad y guía de las excavaciones, Barcelona.

ALMAGRO, M. (1975): Segobriga (Ciudad celtibérica y romana), Madrid.

ALARCÃO, J. DE Y ÉTIENNE, R. (1977): Fouilles de Conimbriga I. L'Archictecture, Paris.

ALVARGONZÁLEZ, C. (1903): Termas romanas de Campo Valdés, Gijón (1965).

AQUilué, X., CASTANYER, P., SANTOS, M. Y TREMOLEDA, J. (2002): "Primers resultats del projecte d'intervenció arqueològica a les termes públiques de la ciutat romana d'Emporiae (Empúries, L'Escala, Alt Empordà)", La gestió de

2000; López Quiroga y Rodríguez Martín, 2000-2001. $133 \mathrm{Ya}$ en prensa este trabajo ha salido a la luz el libro de Pilar Reis, 2004 que no queremos dejar de mencionar. 
l'aigua a les ciutats romanes d'Hispània, Empúries 53, 241-260.

ARRIBAS DOMÍNGUEZ, R. (1999): "Hypocausta en la Lusitania romana. El hypocausto de la villa de El Saucedo (Talavera la Nueva, Toledo)", XXIV C.N.A. (Cartagena, 1997), vol. 4, 383-393.

ARRIBAS DOMÍNGUEZ, R. (1999b): "Los balnea privados en el ámbito rural lusitano. Observaciones preliminares sobre los modelos arquitectónicos”, en Gorges, J-G y Rodríguez Martín, F. G.: Economie et territoire en Lusitanie romaine, Casa de Velázquez 65, Madrid, 427-451

BALIL, A. (1960): "El mosaico romano de la Iglesia de San Miguel”, CAHC I, 21-74.

BALIL, A. Y MONDELO, R. (1985): "Mosaico con representación de peces hallado en las proximidades de Tarragona”, B.S.A.A. LI, 251-256.

BARRAL, X. (1978): Les mosaïques romaines et médiévales de la Regio Laietana (Barcelone et ses environs), Barcelona.

BARRIENTOS, T. (1997): "Baños romanos en Mérida. Estudio preliminar”, Mérida. Excavaciones arqueológicas 1994-1995. Memoria, 259-284.

BELTRÁN, M. (1976): "Arqueología e Historia de las ciudades antiguas del Cabezo de Alcalá de Azaila (Teruel)", Monografías arqueológicas 19, 147-150.

BELTRÁN LLORIS, M. ET ALII, (1987): Arcobriga (Monreal de Azaila), Zaragoza.

BERGES, M. (1970): "Las ruinas de "Els Munts" (Altafulla, Tarragona)", Información Arqueológica 3, 81-87.

BIERS, W. (1988): Mirobriga. Investigations at an Iron Age and Roman site in Southern Portugal by the University of Missouri-Columbia, BAR Int. Series 451, Oxford, 1988.

BLANCO, A. Y LUZÓN, J. Ma (1974): El mosaico de Neptuno de Itálica, Sevilla.

BOBADILLA, M. (1969): "El mosaico de peces de La Pineda (Tarragona)", Pyrenae V, 141-153.

BOUET, A. (1996): Les thermes privés et publics en Gaule Narbonnaise, Thèse de Doctorat Nouveau Régime. Université d'Aix-Marseille III. Aix-en-Provence.

BOUET, A. (1999): Les matériaux de construction en terre cuite dans les thermes de la Gaule Narbonnaise, Ausonius Publications 1, Bordeaux.

BOUET, A. (2000): "Les modèles thermaux et leur diffusion en Gaule" , en Fernández Ochoa, C. y GarcíaEntero, V. (Eds.): Termas Romanas en el Occidente del Imperio, Gijón, 2000, 35-46.

BOUET, A. (2003): “Les thermes privés et publics en gaule Narbonnaise, CEFR, 320, Roma.
BRÖEDER, E. (1983): Die römischen Thermen und das antike Badewesen, Darmstadt.

BROISE, H. Y THÉBERT, Y. (1993): Recherches archéologiques franco-tunisiennes à Bulla Regia III. Les architectures. 1 Les Thermes memmiens, EFR 28/II, 1, ParisRome.

BURGI, J. Y HOPPE, R. 1985: Schleitheim-Iuliomagus. Die römischen Thermen, Basel.

CABRÉ, J. (1944): Corpus Vasorum Hispanorum. Cerámica de Azaila. Museo arqueológico de Madrid, Barcelona y Zaragoza, Madrid.

CARANDINI, A. Y PANELLA, C. (1977): Le terme del Nuotatore. Scavo dell'artibiente 160 y dell'area 25, Roma.

CELIS SÁNCHEZ, J., GUTIÉRREZ GONZÁLEZ, Ma J. Y LIZ GUIRAL, J., (2002): "Nuevos datos y aportaciones a la secuencia cultural de la ciudad de Lancia (Villasabariego, León, España)", Zephyrus $55,257-282$.

CHAVARRÍA ARNAU, A. (1996): “Transformaciones arquitectónicas de los establecimientos rurales en el nordeste de la Tarraconensis durante la Antigüedad Tardía", Butlletí de la Real Acadèmia catalana de Belles Arts de Sant Jordi X, 165-202.

CHAVARRÍA ARNAU, A. (1997): "Las transformaciones termales en las uillae de la Antigüedad tardía hispánica: la uilla de "Els Ametllers" en Tossa de Mar (Girona)", en Pérex Agorreta, M. J. (ed.): Termalismo Antiguo I Congreso Peninsular, Madrid, 511-518.

CHAVARRÍA ARNAU, A. (1998): "Els establiments rurals del Llevant de la Tarraconesa durant l'antiguitat tardana: transformacions arquitectòniques i funcionals", Annals de $l$ Institut d Estudis Gironins XXXIX, 9-30.

CICERNIA, P. Y MARINUCHI, P. (1992): Scavi di Ostia XI. Le terme del Foro o di Gavio Massimo, Roma.

COMAS SOLÀ, M., PADRÓS MARTÍ, P., GURRI COSTA, J., GURRI COSTA, E. Y GRASSES, Q. (2000): "Las termas romanas de Baetulo (Badalona): un ejemplo de aplicación de las últimas tecnologías en imagen virtual", en Fernández Ochoa, C. y García-Entero, V.: Termas Romanas en el Occidente del Imperio, Gijón, 429-435.

CORZO, R. (1991): Las termas, la ciudad y el Río de Sevilla en la Antigüedad. Excavaciones en la calle Abades, Sevilla.

CUYÀS TOLOSA, J. M. (1947): "Interesante hallazgo arqueológico: los baños romanos de Baetulo", Revista de Badalona, 14 agosto de 1947.

DE LOS RÍOS, D. (1861): “Terme d'Italica”, Annali dell'Instituto di Correspondenza Archeologica, 375-379. 
DEGBOMONT, J. M. (1984): Hypocaustes. Le chauffage par hypocauste dans l'habitat privé, Liege.

DELAINE, J. (1988): Recent research on Roman Baths, JRA 1, 11-32.

DELAINE, J. (1997): The Baths of Caracalla. A study in the design, construction, and economics of large-scale building projects in Imperial Rome, JRA Inter. Series 25, Portsmouth.

DELAINE, J. AND JOHNSTON, D. E. (EDS.) (1999): Roman Baths and Bathing, Proceedings of the $7^{\text {st }}$ International Conference on Roman Baths (Bath, 30 March-4 April 1992), JRA Suppl. Series 37.

DÍAZ GARCÍA, M., GARCÍA NOGUERA, M. Y MACÍAS SOLÉ, J. M. (2000): "Las termas públicas de Tarraco: estudio preliminar", en Fernández Ochoa, C. y García-Entero, V. (eds.): Termas romanas en el Occidente del Imperio, Gijón, 163-169.

DÍAZ GARCÍA, M., GARCÍA NOGUERA, M. Y MACÍAS SOLÉ, J. M. (2000b): "Les termes públiques de Tarragona: excavacions en el carrer de Sant Miquel, núm. 33. Estudi preliminar", en Ruíz de Arbulo, J. (ed.) 2000: Tàrraco 99: Arqueologia d'una capital provincial romana. Actes de les jornades d'arqueologia sobre intervencions a la ciutat antiga $i$ al seu territori (1993-1999), Tarragona (1999), 111-133.

DIAZ GARCIA, M. Y MACIAS, J. Ma (2003): "Les themes publiqres de Tàrraco, Empúries, la gestió de l'aigua a les cintats romanes d'Hispania 53,48-51

DUNBABIN, K. (1989): "Baiarum grata voluptas: pleasures and dangers of the baths", PBSR LVII n.s. XLIV, 6-46.

ELVIRA, M. A. (1984): "Catas n ${ }^{\circ}$ 6, 7 y 8 (Piscina frigidarium)", Castulo IV, EAE 131, Madrid.

ESCHEBACH, M. (1979): Die Stabianer Thermen in Pompeji, Berlín.

ESCRIVÀ, V. Y RIBERA, A. (1993): "Avanç a l'estudi de les termes romano-republicanes de Valentia", en Mar et alii (eds.): Utilització de laigua a les ciutats romanes. Documents d'Arqueología Clàssica 0. Tarragona, 139-186.

ESCRIVÀ, V., MARTÍNEZ CAMPS, C. Y VIDAL FERRÚS, X. (2001): "Edeta kai Leiria. La ciutat d'Edeta de l'època romana a l'antiguitat tardana", Lauro 9, 11-91.

ÉTIENNE, R. (1960): Le quartier nord-est de Volubilis, Paris.

ÉTIÉNNE, R. Y MAYET, F. (1971): "Briques de Bélo. Relations entre la Mauretanie Tingitana et la Bétique au Bas Empire", MCV 7, 59-74.

FAGAN, F. G. (1999): Bathing in Public in the Roman World, Michigan.

FAGAN, F. G. (2001): The genesis of the Roman Publics
Baths: Recent approches and future directions, $A J A$ 105,3 403-426

FARRIGTON, A. (1995): The roman baths of Lycia. An architectural study, Ankara.

FERNÁNDEZ-GALIANO, D. (1987): Mosaicos romanos del Convento Caesaraugustano, Zaragoza.

FERNÁNDEZ OCHOA, C. (dir.) (1995): Termas romanas de Campo Valdés, Gijón.

FERNÁNDEZ OCHOA, C. (dir.) (1997): Termas romanas de Campo Valdés, Gijón.

FERNÁNDEZ OCHOA, C. (1998): "Edificios para el ocio", en Complutum. Roma en el interior de la Península Ibérica. Catálogo de Exposición, Alcalá de Henares. 78-87.

FERNÁNDEZ OCHOA, C. (2002): "La ciudad romana de Gijón (Asturias, España)”, en Los Baños públicos como símbolo de romanizad. Espacios de ocio, convivencia y cultura en el arco atlántico, Gijón, 29-48.

FERNÁNDEZ OCHOA, C. Y GARCÍA DÍAZ, P. (2000): "Recuperación y puesta en valor de las termas romanas de Campo Valdés de Gijón (Asturias)", en Fernández Ochoa, C. y García-Entero, V.: Termas romanas en el Occidente del Imperio, Gijón, 443-449.

FERNÁNDEZ OCHOA, C. Y GARCÍA-ENTERO, V., (1999): "Las termas romanas del Noroeste y de la Meseta norte de Hispania. Los modelos arquitectónicos", AEspA 72, 141-166.

FERNÁNDEZ OCHOA, C. Y GARCÍA-ENTERO, V. (Eds.) (2000): Termas romanas en el Occidente del Imperio, Actas del II Coloquio Internacional de Arqueología en Gijón, Gijón (1999).

FERNÁNDEZ OCHOA, C. Y ZARZALEJOS PRIETO, M. (1996): "Técnicas constructivas en las termas romanas de Campo Valdés (Gijón): El material latericio", AEspA 69, 109-118.

FERNÁNDEZ OCHOA, C. Y ZARZALEJOS PRIETO, M. (2001): "Las termas públicas de las ciudades hispanas en el Bajo Imperio", en García Moreno, L. y Rascón, S. (eds.): II Encuentro Hispania en la Antigüedad Tardía: Ocio y espectáculos, Acta Antiqua Complutensia II, (Alcalá de Henares, 1997), Madrid, 19-35.

FERNÁNDEZ OCHOA, C., MORILLO, A., ZARZALEJOS, M. Y GARCÍA-ENTERO, V. (1997): "Las termas romanas de Hispania: Balance historiográfico y perspectivas de investigación", en Pérex Agorreta, M. J. (ed.): I Congreso peninsular de Termalismo Antiguo, (Arnedillo, 1996), Madrid, 381389.

FERNÁNDEZ OCHOA, C., MORILLO, A. Y ZARZALEJOS, M. (1999): "Material latericio en las termas romanas de Hispania”, en Bendala, M., 
Rico, Ch, y Roldán, L. (eds.): El ladrillo y sus derivados en la época romana. Monografías de Arquitectura romana 4, Madrid, 291-305.

FERNÁNDEZ OCHOA, C., MORILLO, A. Y ZARZALEJOS, M. (2000): Grandes conjuntos termales públicos en Hispania, en Fernández Ochoa, C. y García-Entero, V.: Termas romanas en el Occidente del Imperio, Actas del II Coloquio Internacional de Arqueología en Gijón, Gijón, 59-72.

FERNÁNDEZ RODRÍGUEZ, L. E., SÚAREZ PADILLA, J., CISNEROS GARCÍA, M ${ }^{\mathrm{a}}$ I., SALADO ESCAÑO, J. B. Y NAVARRO LUENGO, F. (2001): "Restos de un edificio termal en la Abadía de Santa Ana del Cister. Última aportación al conocimiento de la Malaca Altoimperial”, $A A A^{\prime} 98 . I I I .2$, 504-511.

FERRERUELA, A. Y MINGUEZ, S.A.2003: Dos modelos de implantación urbana tardorrepublicana en el Valle Médio del Ebro: Las ciudades de Caboñeta y la Corona, AESPA 76, 247, 262.

FERRERUELA, A. Y MINGUEZ, S.A.2002: La Caboñeta (El Burgo de Ebro, Zaragoza) en Jiménez Salvador, s.l. y Ribera Lacomba A. (coord): Valencia, las primera ciudades romanas en Hispania, Valencia 205214.

FINCKER, M. (1986): "Les briques claveaux: un matériau de construction spécifique des thermes romains", Revue Aquitania 4, 143-150.

FUENTES DOMÍNGUEZ, A. (2000): "Las termas en la Antigüedad Tardía: reconversión, amortización, desaparición. El caso hispano", en Fernández Ochoa, C. y García-Entero V. (Eds.): Termas romanas en el Occidente del Imperio, Gijón, 135-145.

GARCÍA Y BELLIDO, A. (1970): "Estudios sobre la Legio VII Gemina y su campamento en León”, Legio Septima Gemina, León.

GARCÍA-ENTERO, V., (1997): Las termas de las villae hispanorromanas: Provincia Tarraconense (Análisis constructivo y funcional). Memoria de Licenciatura Inédita. Universidad Autónoma de Madrid.

GARCÍA-ENTERO, V., (1997b): "El conjunto termal de la llamada villa del Camino Viejo de las Sepulturas (Balazote, Albacete)", Espacio, Tiempo y Forma $\mathrm{H}^{\mathrm{a}}$ Antigua, Serie II, 10, 327-350.

GARCÍA-ENTERO, V., (1999): "Las termas de las villae leonesas: Modelos arquitectónicos y funcionales", XXIV C.N.A. (Cartagena, 1997) vol. 4, 375-382.

GARCÍA-ENTERO, V., (2000): "Bene Lava: una amplia oferta a disposición del público", Revista de Arqueología 227, 38-47.

GARCÍA-ENTERO, V. Y ARRIBAS, R. (2000): Los balnea de las villae y su proceso de monumentalización, en Fernández Ochoa, C. y García-Entero, V. (eds.):
Termas Romanas en el Occidente del Imperio, Gijón (1999), 83-96.

GARCÍA-ENTERO, V., (2001): Los balnea de las villae hispanorromanas: provincia Tarraconense, Monografias de arquitectura hispanorromana 5, Serie Termas 1, Madrid.

GARCÍA-ENTERO, V. (2001b): "Reflexiones en torno a las termas de las villae hispanorromanas. El material constructivo: Cronología y dispersión geográfica”, en García Moreno, L. y Rascón Marqués, S. (eds.): Ocio y Espectáculo en la Antigüedad Tardía, II Encuentro Hispania en la Antigüedad Tardía, Acta Complutensia II, (Alcalá de Henares, 1997), Madrid, 59-78.

GARCÍA-ENTERO, V. (2003): Los edificios termales privados domésticos -ámbito rural y urbanos- en la Hispania romana, Tesis Doctoral Inédita, Dpto. Prehistoria y Arqueología U.A.M., Madrid.

GARCÍA-ENTERO, V. (2004): "Nueva propuesta interpretativa de la llamada Casa de Hippolytus de Complutum (Alcalá de Henares, Madrid). Un complejo termal suburbano", AEspA 77, 143-158.

GARCÍA-ENTERO, V., (2005 e.p.): Las transformaciones de los balnea rurales domésticos durante la Antigüedad tardía en Hispania (siglos IV - VI d.c.), CUPAUAM 32

GARCÍA-ENTERO, V., (2006): Los Balnea domésticos en la Hispania Romana, anejos de AESPA XXXVIII, Madrid.

GARCÍA-MARCOS, V. (1994): Descubrimiento de unas nuevas termas públicas en Asturica Augusta (León, Asturias), Cuadernos Municipales 2, Astorga.

GARCÍA-MARCOS, V. Y BURÓN, M. (2000): "Las termas menores de Asturica Augusta, en Fernández Ochoa, C. y García-Entero, V. (eds.): Termas romanas en el Occidente del Imperio, Gijón, 297-214.

GASPAR, A., SANDE, F. Y DELGADO, M. (1986): "O Salvamento de Bracara Augusta", I Encontro Nacional de Arqueologia Urbana, Lisboa (1985), 27-42.

GHINI, G. (1988): Le terme Alessandrine nel Campo Marzio, Roma.

GIL, I., LORIENTE, A., MORÁN, M., PAYÀ, X. Y PÉREZ ALMOGUERA, A. (2001): "De la Iltirta prerromana a la Ilerda tardorromana. Nuevos datos tras dos décadas de investigación continuada en Lérida", AEspA 74, 161-181.

GUARDIA, M. (1992): Los mosaicos de la Antigüedad Tardía en Hispania. Estudios de iconografía, Barcelona.

GUIRAL PELEGRÍN, C. Y MARTÍN-BUENO, M. (1996): Bilbilis I. Decoración pictórica y estucos ornamentales, Zaragoza. 
GUITART, J. (1976): Baetulo. Topografía arqueológica, urbanismo e historia. Monografías Badalonesas, Badalona.

GUITART, J. Y PADRÓS, P. (1990): "Baetulo. Cronología y significación de sus monumentos", en Trillmich, W. y Zanker, P. (eds.): Stadbild und Ideologie, München, 165-175.

HAAN, N. DE (1993): "Dekoration und Funktion in den Privatbädern von Pompeji und Herculaneum”, en Moormann, E. M. (ed.): Functional and spatial Analysis of wall paintings, Proceedings of the Fifth International Congress on Ancient Wall Painting, Amsterdam (1992), Leiden, 34-37.

HIDALGO PRIETO, R. (1996): Espacio público y espacio privado en el conjunto palatino de Cercadilla (Córdoba): El aula central y las termas, Colección Arqueología, Serie Monografías Cercadilla 1, Sevilla.

HIDALGO PRIETO, R. (1996b): "Sobre la interpretación de las termas de Cercadilla (Córdoba)", Habis 27, 189-203.

JACOBELLI, L. (1987): "Lo scavo delle Terme Suburbane. Notizie preliminari", Rivista di Studi Pompeiani 1, 151-154.

JACOBELLI, L. (1988): "Terme Suburbane: Stato attuale delle conoscienze", Rivista di Studi Pompeiani 2, 202-208.

JACOBELLI, L. (1995): Le pitture eroriche delle terme suburbane di Pompei, Ministero per i beni culturali ed ambientali, Sorpintendenza archeologica di Pompei, Monografie 10, Roma.

JORDÁ, F. (1962): Lancia. Excavaciones arqueológicas en España 1. Madrid.

KRENCKER, D., KRÜGER, E., LEHMANN, H. Y WACHTLER, H. (1929): Die trierer Kaiserthermen. Augsburg.

KRETZSCHMER, F. (1953): "Hypokausten", SaalbJb12, 841.

KOLOSKI OSTROW, A. (1990): The Sarno Bath Complex, Soprintendenza Archeologica di Pompei, Monografia 4, Napoli.

LENOIR, É. (1991): “Thermes romains de Maurétanie Tingitane", en AAVV: Les Thermes Romais, CEFR $142,151-160$.

KOPPEL, E. Ma (1993): "La escultura del entorno de Tarraco: las villae", Actas de la I Reunión sobre escultura romana en Hispania, Mérida, 221-237.

KOPPEL, E. Ma (1995): "La decoración escultórica de las villae romanas en Hispania", en Noguera Celdrán, J. M. (Coor.) 1995: Poblamiento rural romano en el sureste de Hispania, (Jumilla 1993), Murcia, 27-48.
KOPPEL, E. Ma (2000): "Informe preliminar sobre la decoración escultórica de la villa romana de Els Munts (Altafulla, Tarragona)", MM 41, 380-394.

KOPPEL, E. Ma (2004): "La decoración escultórica de las termas en Hispania", en Nogales Basarrate, T. y Gonçalves, L. J. (Coor.): Actas de la IV Reunión sobre escultura romana en Hispania, (Lisboa, 2002) Madrid, 339-366.

LEBLANC, O. Y LEBOT-HELLY, A. (1997): "Les décors peints des petits thermes nord à Saint-Romain-enGal (Rhône)", Gallia 54, 262-276.

LEÓN, P. (1977-1978): "Notas sobre técnica edilicia en Itálica”, AEspA 50-51, 143-163.

LIZ GUIRAL, J., CELIS SÁNCHEZ, J. Y GUTIÉRREZ GONZÁLEZ, M. J. (2000): "Las termas de Lancia (Villasabariego, León, España)", en Fernández Ochoa, C. y García-Entero, V. (eds.): Termas romanas en el Occidente del Imperio, Gijón, 221-228.

LÓPEZ QUIROGA, J. Y RODRÍGUEZ MARTÍN, F. G. (2000-2001): "El "final" de las villae en Hispania, I. La transformación de las pars urbana de las villae durante la Antigüedad Tardía", Portugalia Nova Série XXI-XXII, 137-190.

LOSTAL, J. (1980): Arqueología del Aragón romano, Zaragoza.

LUENGO, J. M. (1956-1961): Astorga romana y su entorno. Excavaciones del Plan Nacional 1954-1955, NAH 5.

MACÍAS SOLÉ, J. Ma (2003 e.p.): "Làrea portuària de Tarracona”, VI Reunió d'Arqueologia Cristiana Hispànica, Valencia (2003), preactas, 46.

MACÍAS SOLÉ, J. Ma (e.d.) (2004): "Les thermes públiques de l'area portuária de Tárraco. carrer de Sant Miguel de Tarragona, Institut Catalá d'arquelogia clásica, série documenta 2, Tarragona.

MAGALlÓN, M. A., SILliÈRES, P., NAVARRO, M., SÁENZ, J. C., GUIRAL, C., FINCKER, M. LABERTHE, J. M., FABRE, J. M. Y RICO, CH., (1994): "Labitosola (La Puebla de Castro, Huesca). Informe de la $4^{\text {a }}$ campaña de excavaciones", Bolskan 11, 89-132.

MAGAllón, M. A., MÍNGUEZ, J. A., ROUX, D. Y SILLIÈRES, P. (1995): "Labitolosa (La Puebla de Castro, Huesca). Informe de la campaña de excavación de 1992", Caesaraugusta 71, 91-147.

MAGALlÓN, M. A., MÍNGUEZ, J. A., NAVARRO, M., FABRE, J. M., RICO, CH. Y SILLIÈRES, P. (1995b): "Labitolosa (Cerro del Calvario, La Puebla de Castro, Huesca), Informe de la campaña de excavación", Caesaraugusta 71, 147-227.

MAGALlÓN, M. A., SILliÈRES, P., NAVARRO, M., SÁENZ, J. C., FINCKER, M. Y LABERTHE, J. M., 
(1997): "Informe de la $5^{\mathrm{a}}$ y $6^{\mathrm{a}}$ campaña de excavaciones. 1995-96”, Bolskan 14, 117-156.

MANDERSCHEID, H. (1981): Die Skulpturenausstattung der kaiserzeitlichen Thermenanlagen, Berlin.

MANDERSCHEID, H. (1988): Bibliographie zum römischen Badewesen unter besonderer Berücksichtigung der öffentlichen Thermen, Munich.

MANDERSCHEID, H. (1988b): Römische Thermen. Aspekte von Architektur, teclinik und Ausstattung, Die Wasserversorgung antiker Stádte, 2.

MANDERSCHEID, H. (2004): Ancient baths and bating: a bibliography for the years 1988-2001, JRA, Supp. series 55, portsmouth.

MAÑANES, T. (1983): Astorga romana y su entorno. Estudio arqueológico. Valladolid.

MAR MEDINA, R. (1990): "Las termas de tipo medio en Ostia y su inserción en el espacio urbano. Estudio Preliminar", Itálica 18, 31-77.

MAR MEDINA, R. (1991): "La formazione dello spazio urbano nella città di Ostia”, MDAI(Rom) 98, 81-109.

MAR MEDINA, R. (ED.) (2001): El Santuario de Serapis en Ostia, Documents d'Arqueologia Clàssica 4, Tarragona.

MAR MEDINA, R., LÓPEZ, J. Y PIÑOL, LL. (ED.) (1993): Utilització de l aigua a les ciutats romanes. Documents d'Arqueología Clàssica 0. Tarragona.

MARÍN, C. Y RIBERA, A. (1999): Las termas romanas de l'Almoina, Valencia.

MARTÍN, A. (1998-1999): El conjunt arqueològic de Ca l'Arnau: un assentament republicà (Cabrera de Mar, el Maresme), Tribuna d'Arqueologia, 19981999, 211-228

MARTÍN, A. (2000): "Las termas republicanas de Cabrera de Mar (Maresme, Barcelona)", en Fernández Ochoa, C. y García-Entero, V. (eds.): Termas Romanas en el Occidente del Imperio, 157-162.

MARTÍN-BUENO, M. Y LIZ, J. (1989): "Preliminares al estudio de las termas del Municipium Augusta Bilbilis", Segundo encuentro de Estudios Bilbilitanos, I, Calatayud (1986), 83-97.

MARTÍN-BUENO, M. Y Liz, J. (1999): "Las termas del Municipium Augusta Bílbilis y su relación con otros edificios análogos", en DELAINE, J. y JOHNSTON, D. E. (Eds.): Roman Baths and Bathing, Bath (1992), 251-261.

MARTINS, M., DELGADO, M. Y ALARCÃO, J DE. (1994): "Urbanismo e arquitectura de Bracara Augusta: Balanço dos resultados", Trabalhos de Antropología e Etnología, I Congreso de Arqueología Peninsular 34 (1-2), 303-321.
MARTINS, M. Y SILVA, P. (2000): "As termas públicas de Bracara Augusta”, en Fernández Ochoa, C. y García-Entero, V. (eds.): Termas romanas en el Occidente del Imperio, Gijón, 73-81.

MIELSCH, H. (1975):"Neronische und flavische Stuckreliefs inden Vesuvstäden", in Andrade, B. and Kyrieleis, H. (Ed.): Neue Forschungen in Pompeji, Recklinghansen.

MIRÓ I ALAIX, C. Y PUIG I VERDAGUER, F. (2000): "Edificios termales públicos y privados en Barcino", en Fernández Ochoa, C. y GarcíaEntero, V. (eds.): Termas romanas en el Occidente del Imperio, Gijón, 171-178.

MORA, G. (1981): “Termas romanas en Hispania”, AEspA $54,37-89$

MUÑOZ FERNÁNDEZ, E., MORLOTE EXPÓSITO, J. M. Y MONTES BARQUÍN, R. (2000): "Las termas romanas de San Juan de Maliaño (Camargo, Cantabria)", en Fernández Ochoa, C. y GarcíaEntero, V. (eds.): Termas romanas en el Occidente del Imperio, Gijón, 229-235.

NEIRA JIMÉNEZ, L. (1992): "Mosaicos romanos con nereidas y tritones. Su relación con el ambiente arquitectónico en el Norte de Africa y en Hispania”, L'Africa romana. Atti del X Convegno di studio, 1259-1278.

NEIRA JIMÉNEZ, L. (1997): "Algunas consideraciones sobre mosaicos romanos con nereidas y tritones en ambientes termales de Hispania", en Pérex Agorreta, M. J. (ed): Termalismo Antiguo I Congreso Peninsular, Madrid, 481-496.

NIELSEN, I. (1985): "Consideración sulle prime fasi dell'evoluzione dell'edificio termale romano", Analecta Romana Instituti Danici 14, 81-112.

NIELSEN, I. (1990): Thermae et Balnea. The architectural and cultural history of roman public baths, Aarus.

NOGUERA CELDRÁN, J. M. (1994): La escultura romana de la Provincia de Albacete (Hispania CiteriorConventus Carthaginensis). Instituto de Estudios Albacetenses, Serie I, Estudios $n^{0} 76$, Albacete.

NOGUERA CELDRÁN, J. M. (1995): "El Asklepios de Balazote (Albacete)", XXI CNA (Teruel, 1991), 1211-1219.

NOGUERA CELDRÁN, J. M. (2000 e.p.): Ártemis Agrótera. La Diana Cazadora de la "Casa de Hippolytus" de Complutum: Análisis tipológico, estilístico y funcional, en La Casa de Hippolytus: sede de un collegium iuvenum, Cuadernos del Juncal 3, Alcalá de Henares.

NOGUERA CELDRÁN, J. M. (2002): La Venus de Illici, Sittera Scripta in honorem Prof. Lope Pascual Martínez, Murcia, vol. 2, 759-776. 
NOLLA, J. Ma (2000): "Las termas republicanas en Hispania", en Fernández Ochoa, C. y GarcíaEntero, V. (Eds.): Termas romanas en el occidente del Imperio, Gijón, 47-58.

OLCINA, M. Y PÉREZ, R. (1998): La ciudad ibero-romana de Lucentum (El Tossal de Manises, Alicante). Introducción a la investigación del yacimiento arqueológico y su recuperación como espacio público, Alicante.

PALAHÍ, LL. Y VIVÓ, D. (1993): "Termes de la "basílica" d'Empúries", en Mar, R. et alii (eds.): Utilització de l'aigua a les ciutats romanes, Documents d'Arqueologia Clàssica 0, Tarragona, 103-111.

PALAHÍ, LL. Y VIVÓ, D. (1995): "Els precedents. L'edifici termal", en Nolla, J. M. y Sagrera, J.: Civitatis Impuritanae Coementeria. Les necrópolis tardanes de la Neàpolis, Girona, 61-84.

PALLARÉS, F. (1969): "Las excavaciones de la plaza de San Miguel y la topografía romana de Barcino", CAHC XIII, 5-42.

PALLARÉS, F. (1975): "La topografía i els orígens de la Barcelona romana”, CAHC XVI, 5-48.

PALOL, P. (1984): Clunia. Historia de la ciudad y guía de las excavaciones, Burgos.

PANELLA, C. (1978): Le Terme del Nuotatore ad Ostia Antica. Scavo e pubblicazione, Un decennio di ricerche archeologiche, Roma.

PAYÀ I MERCÈ, X., GIL, I., LORIENTE, A., LAFUENTE, A. Y MORÁN, M., (1996): "Evolució espacial i cronològica de l'antiga ciutat d'Ilerda", Revista d'Arqueologia de Ponent 6, 119-149.

PAYÀ I MERCÈ, J. (2000): "Las termas públicas de la ciudad romana de Ilerda”, en Fernández Ochoa, C. y García-Entero, V. (eds.): Termas romanas en el Occidente del Imperio, Gijón, 179-184.

PEÑA CERVANTES, Y. (2000): "Reutilizaciones termales en el noroeste de la Provincia Tarraconense", en Fernández Ochoa, C. y García-Entero, V. (Eds.) 2000: Termas romanas en el Occidente del Imperio, Gijón, 349-354.

PÉREX AGORRETA, M. J. (ed.) (1997): Termalismo Antiguo, I Congreso Peninsular, (Arnedillo, 1996), Madrid.

PÉREZ LOSADA, F. (1992): "Hipocaustos na Galicia romana", Gallaecia 13, 129-176.

RASCÓN MARQUÉS, S. (1995): La Ciudad Hispanorromana de Complutum, Cuadernos del Juncal, 2. Alcalá de Henares.

PRESEDO, F. Y CABALLOS, A. (1985): "Informe de la campaña arqueológica de 1985 en el yacimiento de Carteia (San Roque, Cádiz)”, AAA’85.II, 387-393.
RAMALLO ASENSIO, S. F. (1985): Mosaicos romanos de Carthago Nova (Hispania Citerior), Murcia.

RAMALLO ASENSIO, S. F. (1989-90): "Termas romanas de Carthago Nova y alrededores", APA 5-6, 161-178.

RAMALLO ASENSIO, S. F. Y ROS SALA, Mª M. (1993): Itinerarios arqueológicos de la región de Murcia, Murcia.

RAMOS MOLINA, R. Y TENDERO PORRAS, M. (2000): "Dos nuevos edificios termales en Illici (La Alcudia, Elche)", en Fernández Ochoa, C. y García-Entero, V. (eds.): Termas romanas en el occidente del Imperio, Gijón, 245-250.

REBUFFAT, R., HALLIER, G. Y MARION, J. (1970): Thamusida. Fouilles du Service des Antiquités du Maroc, II, Mélanges d'archéologie et d'histoire Supp. 2, 21-213.

REIS, Ma P. (2004): Las Termas y baños romanos de Lusitania, Strdia Lusitana 1, Madrid

RIBERA, A. (1998): La fundació de València. La ciutat a l'època romanorrepublicana (segles II-I a.C.), Valencia.

RICCIARDI, M ${ }^{\mathrm{a}} \mathrm{A}$, (1997): La civiltà dell'acqua in Ostia Antica, Roma.

RODRÍGUEZ OLIVA, P. (1993): "Nuevas investigaciones sobre el teatro romano de Málaga", en Ramallo Asensio, S. y Santiuste de Pablos, F. (Coords.): Teatros romanos en Hispania, Cuadernos de Arquitectura Romana 2, 183-194.

ROLDÁN GÓMEZ, L. (1992): Técnicas constructivas en Carteia (San Roque, Cádiz), Monografías de Arquitectura Romana 1, Madrid.

ROLDÁN GÓMEZ, L. (1993): Técnicas constructivas en Itálica (Santiponce, Sevilla), Monografías de Arquitectura Romana, 2, Madrid.

ROLDÁN GÓMEZ, L. (1996): Aspects constructifs des thermes romains de la Baetica, L'Africa Romana, XI, 789-821.

ROMO SALAS, A., VARGAS JIMÉNEZ, J. M., DOMÍNGUEZ, E. D. Y ORTEGA GORDILLO, M. (2001): "De las termas a la Mackbara. Intervención aqueológica en la plaza de España de Écija (Sevilla)", AAA'98. III. 2, 979-996.

ROMO SALAS, A. (2002): "Las termas del Foro de la Colonia Firma Astigi (Écija, Sevilla)”, Romula 1, 151-174.

SANMARTÍ, E. (2000): "La cronología del edificio termal predecesor de la cella memoriae de la "Neapolis" y su relación con la amortización del lienzo de levante de la muralla romana de Emporiae (Empúries, L'Escala, Alt Empordà)", en Scripta in Honores Enrique A. Llobregat Conessa, Alicante, 433-442.

SANZ GAMO, R. (1987): "Sistemas de calefacción de 
época romana en la provincia de Albacete", Información Cultural 16, Albacete, 3-14.

SANZ GAMO, R. (1987b): "Algunos materiales romanos utilizados en la construcción de las concamerationes", Oretum III, 225-236.

SANZ GAMO, R. (1987c): "Notas sobre los mosaicos romanos de Balazote (Albacete)", Caesaraugusta 64, 189-210.

SANZ GAMO, R. (1987d): "Mosaicos romanos del Camino Viejo de Las Sepulturas (Balazote, Albacete)", Al-Basit 21, 43-64.

SANZ GAMO, R. (1989): "Materiales cerámicos utilizados en la construcción de hypocaustos en el sureste peninsular: Clavijas y ladrillos recortados”, XIX C.N.A. (Castellón, 1987), 877-883.

SEVILLANO, Ma A. Y VIDAL, J. (2000): "Las termas mayores de Astorga", en Fernández Ochoa, C. y García-Entero, V. (eds.): Termas romanas en el Occidente del Imperio, Gijón, 199-205.

SEVILLANO, Ma A. Y VIDAL, J. (2002): Urbs Magnifica. Una aproximación a la Arqueología de Asturica Augusta (Astorga, León), León.

SILLIÉRES, P. (1995): Baelo Claudia. Une cité romaine de Bétique, Madrid.

SILliÉRES, P., MAGALLÓN, M. A. Y NAVARRO, M. (1995): "El Municipium Labitulosanum y sus notables: Novedades arqueológicas y epigráficas", AEspA 68, 107-130.

STEPHAN, H. (1996): "Las termas públicas de Italica (Santiponce, Sevilla) en su contexto urbanístico", XXIII CNA, II, 155-160.

TAVARES, L. (1986): Área arqueológica de Freixo. Marco de Cavaneses, Freixo.

TAVARES, L. (1997): Tongobriga, Lisboa.

THATCHER, E. A. (1956): The open rooms of the Terme del Foro di Ostia, MAAR 24.
THÉBERT, Y. (1991): "Problèmes de circulation dans les thermes d'Afrique du nord", en AAVV: Les Thermes Romais, CEFR 142, 139-149.

THÉBERT, Y. (2003): Thermes romains d'Afrique du Nord et leur contexte Méditerranéen. Études d'Histoire et d'Archéologie, B.E.F.A.R. 315, Roma.

THOUVENOT, R. Y LUQUET, A. (1951): "Les thermes de Banasa", PSAM 9, 9-62.

TORRECILLA AZNAR, A. (1999): "Materiales de construcción en las termas de la Hispania romana, a propósito de los materiales hallados en la villa de El Saucedo (Talavera la Nueva, Toledo)", XXIV C.N.A. (Cartagena, 1997), Murcia, vol. 4, 397-416.

VENTURA VILLANUEVA, A. (1997): El abastecimiento de agua a la Córdoba romana II, Acueductos, ciclo de distribución y urbanismo, Córdoba.

VIDAL ENCINAS, J. (1986): "Informe preliminar sobre las posibles termas públicas de Asturica Augusta", Asturica 4, 265-275.

VIDAL ENCINAS, J. Y MARCOS CONTRERAS, G.J. (2002-2003): Una construcción romana singular y unas pequeñas termas en el área suburbana de León, Lancia S, 121-139

WARD-PERKINS, B. (1984): From classical antiquity to the Middle Ages: urban public building in northern and central Italy, A.D. 300-850, Oxford.

YEGÜL, F. K. (1992): Baths and Bathing in the Classical Antiquity, New York.

ZEHNACKER, H., HALLIER, G. Y MARION, J. (1965): "Les premiers thermes de Volubilis et la maison à la citerne", MEFR 77, 87-152.

ZEVI, F. Y V. MANNUCCI, V. (1980): "Restauro di un complesso archeologico: le terme di Porta Marina ad Ostia”, Archeologia Laziale, III. 